\title{
Characterization of AcrD, a Resistance-Nodulation- Cell Division-type multidrug efflux pump from the fire blight pathogen Erwinia amylovora
}

\author{
Daniel Pletzer and Helge Weingart ${ }^{*}$
}

\begin{abstract}
Background: Multidrug efflux pumps are membrane translocases that have the ability to extrude a variety of structurally unrelated compounds from the cell. AcrD, a resistance-nodulation-cell division (RND) transporter, was shown to be involved in efflux of highly hydrophilic aminoglycosides and a limited number of amphiphilic compounds in E. coli. Here, a homologue of AcrD in the plant pathogen and causal agent of fire blight disease Erwinia amylovora was identified.

Results: The substrate specificity of AcrD was studied by overexpression of the corresponding gene from a high-copy plasmid in E. amylovora Ea1189-3, which is hypersensitive to many drugs due to a deficiency of the major multidrug pump AcrB. AcrD mediated resistance to several amphiphilic compounds including clotrimazole and luteolin, two compounds hitherto not described as substrates of AcrD in enterobacteria. However, AcrD was not able to expel aminoglycosides. An acrD mutant exhibited full virulence on apple rootstock and immature pear fruits. RT-PCR analysis revealed an induction of acrD expression in infected apple tissue but not on pear fruits. Moreover, a direct binding of BaeR, the response regulator of the two-component regulatory system BaeSR, to the acrD promoter was observed as has already been shown in other enterobacteria.
\end{abstract}

Conclusions: AcrD from E. amylovora is involved in resistance to a limited number of amphiphilic compounds, but in contrast to AcrD of $E$. coli, it is not involved in resistance to aminoglycosides. The expression of acrD was up-regulated by addition of the substrates deoxycholate, naringenin, tetracycline and zinc. AcrD appears to be regulated by the BaeSR two-component system, an envelope stress signal transduction pathway.

Keywords: Plant pathogen, Fire blight, Erwinia amylovora, Multidrug efflux, RND transporter, AcrD

\section{Background}

Erwinia amylovora is the causative agent of fire blight, a destructive, contagious disease of apple, pear, and other rosaceous plants [1]. All aerial parts of the hosts can be infected by the pathogen. E. amylovora enters its host plants through natural openings (e.g., flower nectaries or leaf stomata) and wounds [2]. Upon entry, the fire blight pathogen moves through intercellular spaces towards the xylem [3]. Typical symptoms include flower necrosis, immature fruit rot, shoot curvature (shepherd's crook), bacterial ooze secretion, and cankers on woody tissues

\footnotetext{
* Correspondence: h.weingart@jacobs-university.de

School of Engineering and Science, Jacobs University Bremen, Campus Ring
} 1, 28759 Bremen, Germany

[1]. The most effective method to treat infected plants is pruning to remove all infected tissue.

However, fire blight can infect entire orchards within a single growing season leading to devastating economic losses [4]. Presently, there are no effective therapeutics available to cure fire blight and therefore prevention is considered the best solution to manage this plant disease. Current control efforts are rather rare and rely primarily on antibiotic applications (e.g., streptomycin or oxytetracycline) to protect flowers. However, the use of antibiotics for the management of fire blight is highly controversial due to the potential risk of promoting the emergence and spread of antibiotic resistance [5].

Gram-negative bacteria often possess multidrug efflux transporters within the cytoplasmic membrane, which have been found to recognize and expel a broad range 
of structurally unrelated compounds from the cell [6,7]. Among the multidrug efflux pumps, members of the resistance-nodulation-cell division (RND) family appear to be the most effective efflux systems in Gram-negative bacteria. RND transporters form a tripartite complex, consisting of an inner membrane pump that recognizes and captures the substrates, a periplasmic membrane fusion protein (MFP) and an outer membrane channel $[8,9]$.

AcrAB is the major multidrug efflux pump in E. coli and shows high conservation among Gram-negative bacteria [8,10-12]. AcrD, a close homolog of AcrB, is an RND-type efflux pump characterized as a transporter of aminoglycosides, a highly hydrophilic class of molecules, and as a transporter of several amphiphilic compounds [13,14]. Typically, the inner membrane pump and the periplasmic MFP are co-transcribed in tandem on polycistronic mRNA molecules [15]. Interestingly, this is not the case for $a c r D$, which appears as a single gene and seemingly functions in concert with AcrA, a MFP co-transcribed with AcrB [14].

Both AcrAB and AcrD efflux systems are also present in the plant pathogen E. amylovora. AcrAB has already been characterized as an efflux system required for virulence of E. amylovora in resistance towards apple phytoalexins and for successful colonization of the host plant [16]. AcrAB of E. amylovora showed a similar substrate spectrum as AcrAB of E. coli [17]. In this study, the substrate specificity of AcrD from E. amylovora was characterized and its contribution to virulence in apple and pear analyzed. As it was found that $a c r D$ is expressed only at low levels under in vitro conditions, we were interested in investigating whether the expression of the AcrD transporter in E. amylovora is induced in planta.

Multidrug transporters are often expressed under control of local, as well as, global transcriptional regulators [18]. Current data show that expression of $a c r D$ in E. coli can be induced by the two-component regulatory system BaeSR [19]. Two-component systems (TCS) play an important role in the regulation of physiological processes in response to environmental or cellular parameters and enable bacterial cells to adapt to changing environmental conditions. TCSs typically consist of a membrane-bound histidine protein kinase (HPK) whose autokinase activity is dependent upon sensing a specific environmental stimulus (e.g., nutrients, temperature, $\mathrm{pH}$, toxins or oxidative stress) [20]. The second protein of a TCS is a response regulator, onto which a phosphoryl group is transferred from the phosphorylated HPK, and which functions as a phosphorylation-activated switch that regulates output responses within the cell causing changes in the expression of target genes [21,22].

BaeSR is a TCS that responds cell envelope damages in E. coli [23]. The small core regulon of BaeSR includes the RND-type transporters AcrD and MdtABC and the periplasmic chaperone Spy [24]. The presence of a homologous BaeSR system in E. amylovora, prompted us to analyze the impact of the response regulator BaeR on the expression levels of $a c r D$.

Herein, we report that overexpression of the RND pump AcrD in an acrB-deficient mutant leads to increased resistance to two substrates, clotrimazole and luteolin, previously not described as substrates of AcrD in other enterobacteria. In order to determine the promoter activity in vitro, we utilized a transcriptional fusion of the promoter regions of $a c r A B$ and $a c r D$, respectively, with the reporter gene egfp. We demonstrate that the response regulator BaeR is able to bind to the upstream region of acrD in E. amylovora Ea1189 and to induce $a c r D$ expression. Furthermore, we show that the inactivation of the RND pump AcrD did not result in reduction of virulence of $E$. amylovora on host plants.

\section{Results}

Identification of an acrD homologue in E. amylovora Ea1189 A search with the BLASTP program (NCBI) using the amino acid sequence of AcrD from E. coli K-12 as the query (accession number P24177) identified a homologous sequence in the genome of E. amylovora CFBP1430 (GenBank:EAMY_2508, annotated as $c m e B$ ). The annotated protein EAMY_2508 is 18 amino acids shorter at the $\mathrm{N}$-terminus than the AcrD protein of E. coli. Comparison of the $a c r D$ gene sequences from $E$. coli and $E$. amylovora suggests that the EAMY_2508 gene of E. amylovora CFBP1430 has been annotated with a wrong start codon. Sequence analysis revealed an alternative ATG start codon 54 bp upstream of the annotated EAMY_2508 gene. The 18 amino acids, encoded by the 54 additional nucleotides, are $100 \%$ identical to the $\mathrm{N}$-terminal region of AcrD from E. coli.

We used the genome sequence of E. amylovora CFBP 1430 to design primers to PCR amplify the respective region from the genomic DNA of our model strain $E$. amylovora Ea1189 whose genome sequence is not yet available. The nucleotide sequence of $a c r D$ and its upstream region from E. amylovora Ea1189 show 100\% identity to EAMY_2508 and its upstream region from $E$. amylovora CFBP1430 based on our sequencing results. AcrD is a member of the RND superfamily of transporters belonging to the Hydrophobe/Amphiphile Efflux-1 (HAE1) family (Transporter Classification Database TC \#2.A.6.2.7).

A BLASTP search (NCBI) of the deduced AcrD sequence from $E$. amylovora Ea1189 as query identified homologous multidrug efflux transporters with high degree of sequence identity (78 - 95\%) in several members of the Enterobacteriaceae family (see Additional file 1 for a phylogenetic tree).

A sequence alignment between AcrD from $E$. amylovora Ea1189 and AcrD from E. coli K-12 showed that the proteins share $79 \%$ identity and $89 \%$ similarity with each other (see Additional file 2). Substituted amino acids were distributed throughout the sequence, but they were at 
least $40 \%$ conserved (all substitutions show a physicochemical score of minimum 4) [25-28] and no insertion or deletion was observed.

Analysis of the up- and downstream regions flanking the acrD homologues from E. amylovora, E. coli and $S$. enterica revealed several differences (see Additional file 3) including the two-component system NarQP located upstream of $a c r D$ in E. amylovora. This system is involved in the regulation of anaerobic nitrate/nitrite respiration, and consists of the sensor kinase NarQ and the response regulator NarP. In E. coli and S. enterica, only the sensor kinase NarQ is present upstream of $a c r D$. The response regulator NarP is situated at different positions in the genomes of E. coli and S. enterica. Moreover, the sizes of the NarQ homologues are also disparate. NarQ of $E$. amylovora Ea1189 is a protein consisting of 328 amino acids, whereas the NarQ homologues of E. coli and $S$. enterica consist of 566 amino acids.

The downstream region of acrD of E. amylovora Ea1189 contains an insertion of about $1.5 \mathrm{~kb}$ encoding several small hypothetical proteins.

\section{Transmembrane organization of AcrB and AcrD in E. amylovora}

In a previous study, the transmembrane organization of AcrB and AcrD from E. coli was analyzed in silico, with 12 transmembrane-spanning domains (TMD) and 2 large periplasmic loops predicted in both proteins [14]. A similar approach was accomplished with AcrB and AcrD from E. amylovora Ea1189 using the online tool TOPCONS [29]. Topology analysis predicted the typical 12 TMDs and 2 periplasmic loops between TMD1 and 2 and TMD 7 and 8 for the RND-type efflux pumps AcrB and AcrD from E. amylovora Ea1189 (see Additional file 4).

\section{Phenotypic characterization of the $a c r D$ mutant}

To evaluate the role of AcrD in antibiotic resistance and to identify substrates of this RND-type efflux pump, susceptibility tests of the wild type and the $a c r D$ mutant to a variety of antimicrobial agents were performed. Deletion of acrD resulted in no significant changes in sensitivity to tested aminoglycosides, dyes or detergents. However, the acrD mutant was 2-fold more sensitive to nitrofurantoin, erythromycin, silver nitrate and sodium tungstate in comparison to the wild type (Table 1). The differences in sensitivity were minor but reproducible. Complementation of the $a c r D$ mutant with plasmid pBlueKS.acrD, which carried the $a c r D$ gene of Ea1189 under control of the $\mathrm{P}_{\text {lac }}$, restored resistance to all tested antimicrobials (data not shown).

\section{Expression of $a c r D$ in an $a c r B$-deficient mutant of E. amylovora}

To investigate the substrate specificity of AcrD from Ea1189, overexpression of the corresponding gene from a high-copy plasmid was achieved in E. amylovora mutant Ea1189-3, which is hypersensitive to many drugs due to a deficiency of the major multidrug efflux pump AcrB [16]. Three overexpression plasmids were generated: pBlueKS. acrD, expressing acrD under control of the lac promoter $\left(\mathrm{P}_{\text {lac }}\right)$, pBlueSK.acrD-ext, expressing acrD under control of its native promoter $\left(\mathrm{P}_{\mathrm{acrD}}\right)$ and $\mathrm{pBlueKS}$.acrD-ext, expressing acrD under control of both promoters $\mathrm{P}_{\text {lac }}$ and $\mathrm{P}_{\mathrm{acrD}}$. As a control, a promoterless acrD gene was cloned in the opposite direction of $\mathrm{P}_{\text {lac }}$. These plasmids were mobilized into the $a c r B$-deficient mutant Ea1189-3 and the sensitivity of the transformants to various substrates were determined (Table 1). Ea1189-3(pBlueKS.acrD), expressing acrD under control of $\mathrm{P}_{\text {lac }}$, exhibited elevated resistance to clotrimazole (2-fold), fusidic acid (2-fold), novobiocin (4-fold), hygromycin B (2-fold), cadmium acetate (2-fold), zinc sulfate (2-fold), bile salt (2-fold), deoxycholate (4-fold), and SDS (2-fold). The expression of $a c r D$ under control of its native promoter in Ea1189-3 showed an increase in resistance similar to that of $\mathrm{P}_{\text {lac }}$-controlled $a c r D$ expression (data not shown). When $a c r D$ was under control of both promoters, $\mathrm{P}_{\text {lac }}$ and $\mathrm{P}_{\mathrm{acrD}}$, it conferred elevated resistance. Compared to the control, Ea1189-3(pBlueKS.acrD-ext) displayed increased resistance to clotrimazole (4-fold), fusidic acid (8-fold), novobiocin (16-fold), hygromycin B (2-fold), cadmium acetate (2-fold), zinc sulfate (2-fold), bile salt (8-fold), deoxycholate (8-fold), SDS (2-fold), luteolin (8-fold) and ethidium bromide (2-fold) (Table 1 ).

\section{RND-type efflux pump expression during cellular growth}

To monitor the expression levels of the RND-type efflux pumps AcrAB and AcrD at different growth states, total RNA was isolated at distinct optical densities and expression levels analyzed by quantitative RT-PCR. The expression values were normalized to the highest expression of the $a c r A$ and $a c r D$ transcript, respectively (Figure 1A). While the expression levels of acrA changed during the cell cycle, indicating a growth phase-dependent transcription with the highest expression in the early exponential phase, acrD showed constant expression during growth. Additionally, the constant expression of $a c r D$ was also connected to a low expression level as determined by $C_{t}$ values (data not shown).

Furthermore, we studied the effect of temperature on activation of the RND-type efflux pump AcrD using qRT-PCR. Bacteria were cultured in $\mathrm{LB}$ broth at $18^{\circ} \mathrm{C}$ and $28^{\circ} \mathrm{C}$, respectively, where $28^{\circ} \mathrm{C}$ represents the optimal growth temperature and $18^{\circ} \mathrm{C}$ represents the temperature at which several genes involved in pathogenicity showed induction in E. amylovora [30,31]. However, no temperature dependence of the acrD expression was observed in vitro (data not shown). 
Table 1 Antimicrobial susceptibility profiles from an E. amylovora wild-type strain, acrD mutant, acrB mutant complemented with AcrD-overexpression plasmids pBlueSK.acrD ( $a c r D$ under control of $P_{\text {lac }}$ ) and pBlueKS.acrD-ext ( $a c r D$ under control of $\mathrm{P}_{\mathrm{lac}}$ and its native promoter $\mathrm{P}_{\mathrm{acrD}}$ ) and $a c r B$ mutant complemented with control plasmid pBlueSK.acrD ( $a$ crD in opposite orientation to $P_{\text {lac }}$ )

\begin{tabular}{|c|c|c|c|c|c|}
\hline \multirow[t]{2}{*}{ Drug } & \multicolumn{5}{|c|}{$\mathrm{MIC}(\mu \mathrm{g} / \mathrm{ml})^{a}$} \\
\hline & Ea1189 & Ea1189.acrD & $\begin{array}{c}\text { Ea1189-3 (pBlueSK.acrD) } \\
P_{\text {lac }}<<a c r D\end{array}$ & $\begin{array}{c}\text { Ea1189-3 (pBlueKS.acrD) } \\
P_{\text {lac }}>>a c r D\end{array}$ & $\begin{array}{c}\text { Ea1189-3 (pBlueKS.acrD-ext) } \\
\mathrm{P}_{\mathrm{lac}}, \mathrm{P}_{\mathrm{acrD}}>>\text { acrD }\end{array}$ \\
\hline
\end{tabular}

\section{Antimicrobials}

\begin{tabular}{|c|c|c|c|c|c|}
\hline Benzalkonium chloride & 12.5 & 12.5 & 1.2 & 1.2 & ND \\
\hline Chloramphenicol & 3.1 & ND & 1.2 & 1.2 & 1.2 \\
\hline Clotrimazole & $>1000$ & $>1000$ & 6.2 & 12.5 & 25 \\
\hline Fusaric acid & 500 & 500 & 500 & 500 & 500 \\
\hline Fusidic acid & 250 & 250 & 3.1 & 6.2 & 25 \\
\hline Genistein & $>5000$ & $>5000$ & 62.5 & 62.5 & 62.5 \\
\hline Josamycin & 125 & 125 & 3.1 & 3.1 & 3.1 \\
\hline Luteolin & $>5000$ & $>5000$ & 15.63 & 15.6 & 125 \\
\hline Naladixic acid & 2.5 & 2.5 & 1.2 & 1.2 & 1.2 \\
\hline Naringenin & 5000 & 5000 & 312 & 312 & 312 \\
\hline Nitrofurantoin & 25 & 12.5 & 12.5 & 12.5 & 12.5 \\
\hline Norfloxacin & 0.63 & 0.63 & 0.03 & 0.03 & 0.03 \\
\hline Novobiocin & 250 & 250 & 6.2 & 25 & 100 \\
\hline Phloretin & 5000 & 5000 & 625 & 625 & 625 \\
\hline Rifampicin & 12.5 & 12.5 & 12.5 & 12.5 & 12.5 \\
\hline Tetracycline & 1.5 & 1.5 & 1.2 & 1.2 & 1.2 \\
\hline \multicolumn{6}{|l|}{ Aminoglycosides } \\
\hline Amikacin & 2.5 & 2.5 & 2.5 & 2.5 & 2.5 \\
\hline Gentamicin & 2.5 & 2.5 & 2.5 & 2.5 & 2.5 \\
\hline Hygromycin B & 100 & 100 & 62.5 & 125 & 125 \\
\hline Streptomycin & 2.5 & 2.5 & 2.5 & 2.5 & 2.5 \\
\hline Tobramycin & 2.5 & 2.5 & 2.5 & 2.5 & 2.5 \\
\hline \multicolumn{6}{|l|}{ Macrolids } \\
\hline Azithromycin & 0.31 & 0.31 & 0.63 & 0.63 & 0.63 \\
\hline Clarithromycin & 0.31 & 0.31 & 0.31 & 0.31 & 0.31 \\
\hline Erythromycin & 0.63 & 0.31 & 0.16 & 0.16 & 0.16 \\
\hline Roxithromycin & 1.25 & 1.25 & 0.16 & 0.16 & 0.16 \\
\hline \multicolumn{6}{|l|}{ Heavy metals } \\
\hline Cadmium acetate & 12.5 & 12.5 & 25 & 50 & 50 \\
\hline Cobalt (II) chloride & 625 & 625 & 1250 & 1250 & 1250 \\
\hline Copper (II) sulfate & 1250 & 1250 & 1250 & 1250 & 1250 \\
\hline Nickel (II) chloride & 1250 & 1250 & 2500 & 2500 & 2500 \\
\hline Silver nitrate & 12.5 & 6.2 & 6.2 & 6.2 & 6.2 \\
\hline Sodium tungstate & 125000 & 62500 & 125000 & 125000 & 125000 \\
\hline Zinc sulfate & 156 & 156 & 156 & 312 & 312 \\
\hline \multicolumn{6}{|l|}{ Dyes } \\
\hline Acriflavine & 50 & 50 & 6.2 & 6.2 & 6.2 \\
\hline Crystal violet & 3.1 & 3.1 & 2.5 & 2.5 & 2.5 \\
\hline
\end{tabular}


Table 1 Antimicrobial susceptibility profiles from an $E$. amylovora wild-type strain, acrD mutant, acrB mutant complemented with AcrD-overexpression plasmids pBlueSK.acrD ( $a c r D$ under control of $P_{\text {lac }}$ ) and pBlueKS.acrD-ext ( $a c r D$ under control of $P_{\text {lac }}$ and its native promoter $P_{\text {acrD }}$ ) and acrB mutant complemented with control plasmid pBlueSK.acrD (acrD in opposite orientation to $\mathbf{P}_{\text {lac }}$ ) (Continued)

\begin{tabular}{|c|c|c|c|c|c|}
\hline Ethidium bromide & 250 & 250 & 3.1 & 3.1 & 6.2 \\
\hline Rhodamine $6 \mathrm{G}$ & $>100$ & $>100$ & 3.1 & 3.1 & 3.1 \\
\hline \multicolumn{6}{|l|}{ Detergents } \\
\hline Bile salt & 5000 & 5000 & 625 & 1250 & 5000 \\
\hline Deoxycholate & $>1000$ & $>1000$ & 312 & 1250 & 2500 \\
\hline SDS & $>1000$ & $>1000$ & 62.5 & 125 & 125 \\
\hline
\end{tabular}

${ }^{a}$ MIC values were determined by the 2-fold dilution assay in three or more independent experiments with similar results. Boldface numbers indicate a higher or lower MIC. ND, not determined.

\section{Promoter activity of $a c r A B$ and $a c r D$ in vitro}

In order to monitor promoter activities of the RND-type efflux pumps AcrAB and AcrD in E. amylovora, transcriptional fusions of the acrA upstream region (140 bp) and $a c r D$ upstream region (210 bp), respectively, to the enhanced green fluorescence protein-encoding gene (egfp) were constructed. To determine whether bacterial growth influenced the promoter activity, fluorescence measurements at several optical densities were performed (Figure 1B). Our data indicated that the promoter activities of both $a c r A B$ and $a c r D$ were constant throughout the growth phases in LB broth. Furthermore, the activity of the $\operatorname{acrD}$ promoter was 4 to 5 -fold lower than the activity of the $\operatorname{acr} A B$ promoter throughout growth.

\section{Effect of substrate exposure on acrD expression}

The expression of genes encoding multidrug efflux systems can be influenced by substrates, which interact with regulatory proteins and therefore increase gene transcription
[32]. Above results prompted us to investigate whether antimicrobials affect the expression of the $a c r D$ gene in E. amylovora. Therefore, we utilized a transcriptional fusion between the promoter region of $a c r D$ and $e g f p$ (pBBR.acrD-Pro.egfp). In order to determine the promoter activity of $a c r D$, we developed a screening assay in a 96-well-plate format. Antimicrobial compounds were added to the plasmid-harboring cells by the 2 -fold dilution method and EGFP fluorescence was determined after 24 hours. Only fluorescence values from substrate concentrations that did not inhibit bacterial growth were plotted versus optical density on a scatter plot (see Additional file 5). Outliers, showing higher fluorescence than the remaining dataset, thus potential inducers of $a c r D$ expression, were identified as deoxycholate, naringenin, tetracycline and zinc sulfate. In the next step, the effect on the activity of the $a c r D$ promoter was evaluated in batch cultures. We included novobiocin and fusidic acid since they were identified as substrates of AcrD in
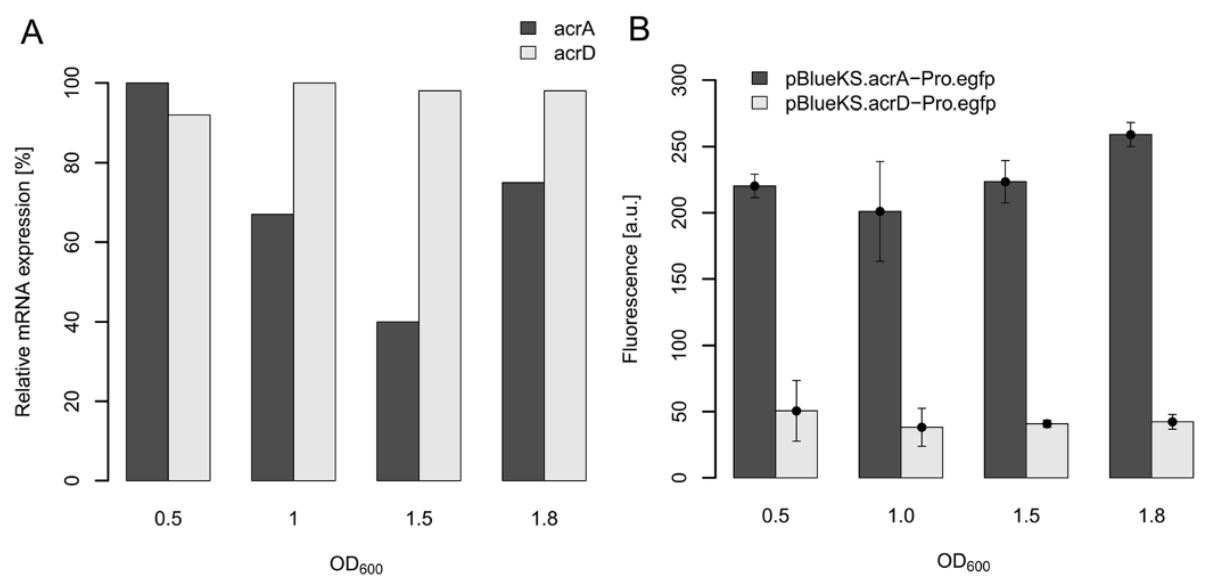

Figure 1 Promoter activities of $a c r A$ and $a c r D$ from Erwinia amylovora. The activity was determined in the course of growth in LB broth, $\mathrm{OD}_{600}$, optical density at $600 \mathrm{~nm}$. (A) Relative mRNA transcript abundance of acrA and acrD during cellular growth of Ea1189 as determined by quantitative RT-PCR. The relative mRNA level was related to the highest average value determined for a gene, which was defined as $100 \%$.

(B) Expression of acrA and $a c r D$ as determined by transcriptional fusions with the reporter gene egfp. E. amylovora wild type was transformed with pBBR.acrA-Pro.egfp and pBBR.acrD-Pro.egfp, respectively. Experiments were performed in triplicates with similar results. 
E. coli $[14,33]$. Additionally, we tested tannin because it displayed a 2-fold induction of acrD in qRT-PCR analysis (data not shown). After 24 hours incubation, the fluorescence signal was measured and normalized to an $\mathrm{OD}_{600}$ of 0.1 (Figure 2). The tested substrates were able to induce the $a c r D$ promoter by approximately 2 to 3 -fold. Among the tested substrates, deoxycholate and zinc, showed significant differences in comparison to the control $(\mathrm{P}<0.05)$.

\section{Contribution of AcrD to virulence of E. amylovora on apple rootstocks}

To study the impact of AcrD on virulence of E. amylovora Ea1189, apple rootstocks MM 106 were infected and the development of disease symptoms was monitored. After one week of incubation all infected shoots showed typical disease symptoms including the shepherd's crook-like bending of the shoot tip, tissue necrosis and ooze formation surrounding the infection site. Furthermore, bacterial populations were counted 1 and 5 day(s) post inoculation, respectively. However, no significant differences between the populations of the wild type and the mutant were observed (Table 2).

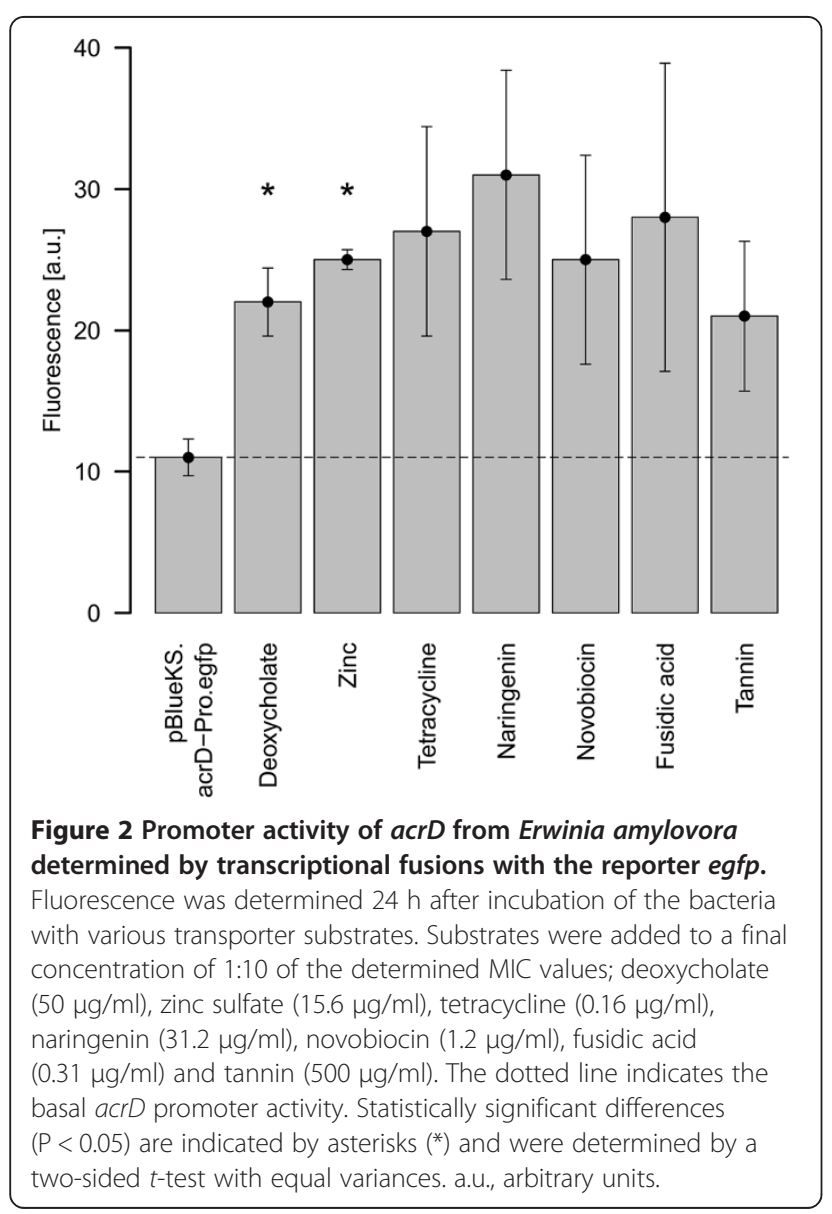

Table 2 Virulence assay on apple rootstock MM 106

\begin{tabular}{lcc}
\hline Strain & \multicolumn{2}{c}{ Re-isolated bacterial cells $^{\boldsymbol{a}}$} \\
\cline { 2 - 3 } & \multicolumn{1}{c}{$\mathbf{~ d p i}$} & \multicolumn{1}{c}{$\mathbf{~ d p i}$} \\
\hline Ea1189 & $2.5 \times 10^{6} \pm 1.1 \times 10^{6}$ & $4.7 \times 10^{8} \pm 1.1 \times 10^{8}$ \\
Ea1189.acrD & $6.1 \times 10^{6} \pm 4.7 \times 10^{6}$ & $3.5 \times 10^{8} \pm 1.1 \times 10^{8}$
\end{tabular}

${ }^{a}$ Bacteria were inoculated by prick technique in the shoot tips with an inoculum of $5 \times 10^{6} \mathrm{CFU} /$ shoot. Establishment of a population of Erwinia amylovora Ea1189 and acrD mutant (CFU/shoot) was determined 1 and 5 days post inoculation (dpi), respectively.

Additionally, immature pear fruits were infected with the wild type and the acrD-deficient mutant and disease symptoms were monitored by means of the diameter of necrotic tissue surrounding the infection site (Figure 3). After 8 days of incubation, when the pear fruit was almost completely necrotic, no significant differences between the wild type and the mutant were observed.

\section{Transcriptional analysis of $a c r A$ and $a c r D$ of $E$. amylovora in planta}

In order to analyze the $a c r A$ and $a c r D$ promoter activities in planta, Ea1189 was infected into shoot tips of apple rootstocks MM 106 as well as into immature pear fruits. Several hours (pears) and days (apple shoots), respectively, after inoculation bacteria were re-isolated by macerating infected plant areas. Total RNA was isolated from recovered cells and transcript abundances of $\operatorname{acr} A$ and $\operatorname{acrD}$ were determined by quantitative RT-PCR. RT-PCR signals of recovered bacteria were compared with RT-PCR signals of Ea1189 cells grown in LB broth to an $\mathrm{OD}_{600}$ of 0.5 .

For immature pear infections, we first determined the expression of the sigma factor HrpL, which coordinates

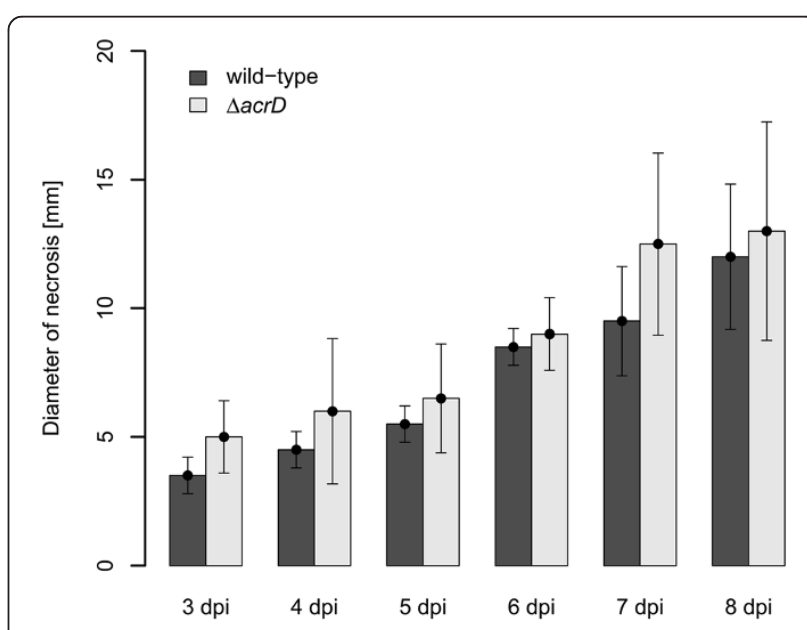

Figure 3 Virulence of Erwinia amylovora Ea1189 wild type and the acrD-deficient mutant on immature pear fruits. Symptoms were monitored starting from the $3^{\text {rd }}$ day post inoculation (dpi) until the fruits were completely necrotic (around $8 \mathrm{dpi}$ ). Data values represent the means of 6 replicates \pm standard deviation. 
the transcription of genes of the hypersensitive response and pathogenicity (hrp) type III secretion system in $E$. amylovora, to identify the time of maximal expression of plant-inducible hrp genes. Compared to growth in LB broth, $h r p L$ expression was 9-fold higher $6 \mathrm{~h}$ post inoculation into immature pears; after $12 \mathrm{~h}$, expression was greatest (40-fold induction), and after $18 \mathrm{~h}$, hrpL expression decreased again (10-fold induction). Hence, we investigated the expression of acrA and acrD genes with Ea1189 cells recovered from infected immature pear fruits $12 \mathrm{~h}$ after inoculation and compared them with cells grown in LB broth to an $\mathrm{OD}_{600}$ of 0.5 (Table 3). Our results indicated that neither $a c r A$ nor $a c r D$ are induced in the early infection phase of immature pear fruits.

For apple rootstock infections, bacteria were re-isolated 1,4 and 7 days after inoculation, respectively, and compared the abundance of $a c r A$ and $a c r D$ transcripts with cells grown in LB broth (Table 3 ). Due to the high activity of the acrA promoter in LB broth, expression analysis by quantitative RT-PCR revealed a down regulation of this gene in planta. On the other hand, since acrD was only expressed at a low level during cellular growth in LB broth, it showed a more than 3-fold induction in planta.

\section{Regulation of the RND-type multidrug efflux pump AcrD in E. amylovora}

In other enterobacteria, e.g., E. coli and S. enterica, BaeR is involved in the regulation of the RND-type efflux pumps MdtABC and AcrD $[19,34]$. BaeR is the response regulator of the two-component system BaeSR, which controls a small set of adaptive factors involved in a unique envelope stress response in E. coli [23]. A BLASTP search using the amino acid sequence of BaeR from E. coli $\mathrm{K} 12$ as the query identified a homologous sequence in the genome of E. amylovora CFBP1430 (GenBank:EAMY_2266). These homologues share $74 \%$ amino acid sequence identity with each other.

In order to test whether BaeR plays a role in the regulation of the acrD promoter in E. amylovora, we analyzed

Table 3 Relative fold-changes in mRNA transcripts of acrA and $a c r D$ after inoculation of Erwinia amylovora Ea1189 on apple rootstocks MM106 and immature pear fruit slices, respectively ${ }^{a}$

\begin{tabular}{|c|c|c|c|c|}
\hline \multirow[t]{2}{*}{ Gene } & \multicolumn{3}{|c|}{ Apple rootstock } & \multirow{2}{*}{$\begin{array}{l}\text { Immature pear } \\
12 \mathrm{hpi}^{\mathrm{c}}\end{array}$} \\
\hline & $1 \mathrm{dpi}^{b}$ & $4 \mathrm{dpi}$ & $7 \mathrm{dpi}$ & \\
\hline acrA & -6.9 & -5.8 & -10.4 & 1.2 \\
\hline$a c r D$ & 3.9 & 3.5 & 3.6 & 1.1 \\
\hline
\end{tabular}

${ }^{a}$ Total RNA was isolated from bacterial cells recovered from infected plant tissues. Transcript abundance of $a c r A$ and $a c r D$ was determined by quantitative RT-PCR and was compared to RT-PCR signal from cells grown in $\mathrm{LB}$ broth to an $\mathrm{OD}_{600}$ of 0.5 .

${ }^{b}$ Bacteria were re-isolated from infected shoots of apple rootstock 1, 4 and 7 days post inoculation (dpi).

${ }^{c}$ Bacteria were re-isolated from infected immature pears 12 hours post inoculation (hpi). whether the published BaeR-binding site sequence motif from E. coli (5'-TTTTTCTCCATDATTGGC-3') is present in the plant pathogen [35]. Indeed we identified a similar motif resembling the BaeR binding box located at position -166 to -148 bp upstream of the coding sequence of $a c r D$ in Ea1189: 5' -TTCTTCACGATTACT GGC-3' (bold letters indicate mismatches to the consensus sequence of $E$. coli).

To confirm the binding of BaeR to the acrD promoter in vitro, an electrophoretic mobility shift assay (EMSA) was performed. DNA fragments used in the EMSA were the Cy5-labeled upstream region of $a c r D$ (246 bp), and as controls, the upstream regions of $\operatorname{acr} A B(205 \mathrm{bp})$ and tolC (291 bp). The DNA fragments were incubated with increasing amounts of purified BaeR protein in presence of nonspecific competitor DNA (Salmon sperm) (Figure 4). The purified BaeR protein showed binding to the upstream region of $a c r D$ with increasing concentrations, which was detected as a smear (Figure 4A). A slight interaction between the $a c r A B$ promoter and BaeR was detected at the highest protein concentration (64 pM), which could suggest an unspecific binding (Figure 4B). No interactions between the fragment of the promoter region of tolC and BaeR were detected (Figure $4 \mathrm{C}$ ). These results show that BaeR binds to the acrD regulatory region and is probably involved in its regulation.

\section{Induction of $a c r D$ through overexpression of BaeR}

Owing to the interaction between the $\operatorname{acrD}$ promoter region and BaeR observed during EMSA assays, we investigated whether overexpression of BaeR may induce the expression of $a c r D$. Therefore, we cloned baeR under an arabinose-inducible promoter (pBAD24.baeR) and performed qRT-PCR analysis 1 hour after induction. Relative fold-changes in mRNA transcripts of $a c r A$ (0.8-fold), $a c r D$ (3.8-fold) and tolC (0.7-fold) were determined. The obtained data values correlate with the observed interaction of BaeR during EMSA indicating a specific binding of BaeR to the regulatory region of $a c r D$.

\section{Discussion}

Bacteria have evolved energy-dependent multidrug efflux pumps in order to prevent intracellular accumulation of toxic compounds, including antimicrobials, antibiotics, dyes and detergents [6,34]. In several enterobacteria, including the human pathogen $E$. coli and the plant pathogen $E$. amylovora, the RND transporter AcrAB-TolC has been described as the major multidrug efflux system providing resistance towards lipophilic and amphiphilic substrates but not towards hydrophilic compounds $[6,16]$. Another member of the RND family, AcrD, has been shown to efficiently efflux highly hydrophilic aminoglycosides from E. coli cells [13]. Here, we identified a gene encoding AcrD in E. amylovora Ea1189, which shows significant sequence 


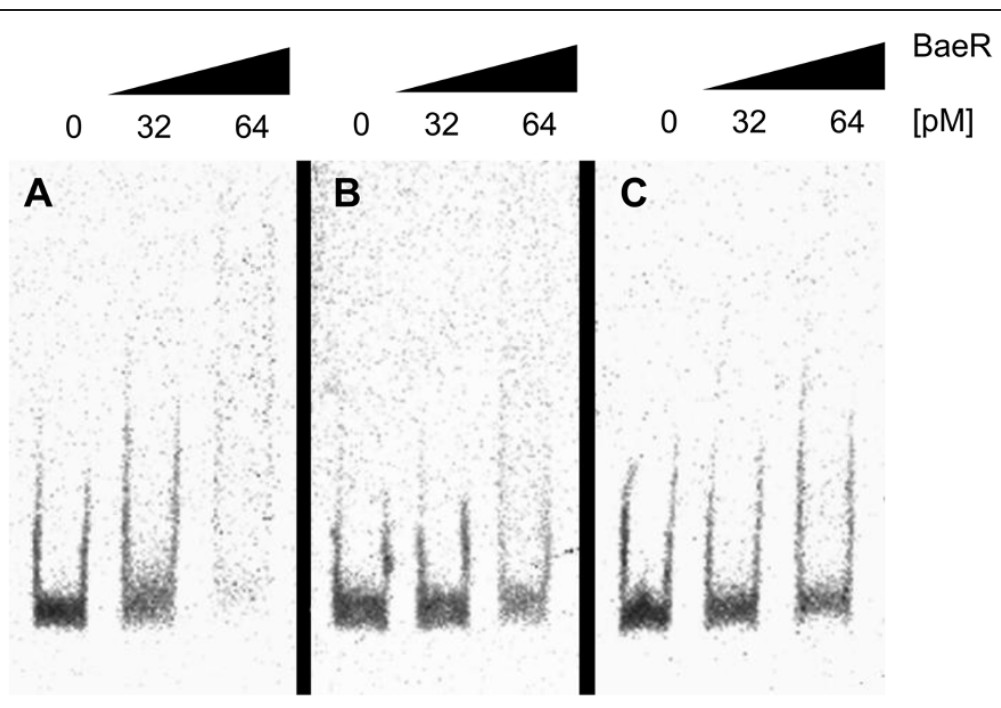

Figure 4 Electrophoretic mobility shift analysis of BaeR interaction with Cy5-labeled DNA fragments. DNA fragments contain the promoter regions of (A) acrD (246 bp), (B) acrA (205 bp) and (C) tolC (291 bp), respectively. Approximately 0.16 pmol of the DNA fragments were incubated with increasing amounts of His-tag purified BaeR (indicated at the top of each lane). The DNA-protein complexes were separated on $4 \%$ non-denaturing polyacrylamide gels.

homology to the cognate aminoglycoside efflux pump of E. coli and investigated the role of this transporter in the fire blight pathogen.

Due to the high level of homology shared by AcrD from E. coli and E. amylovora, it was not surprising to find similar substrate specificities. Previous studies of AcrD in $E$. coli have characterized it as an efflux transporter which provides resistance to hydrophilic aminoglycosides as well as to some amphiphilic compounds such as bile acids, novobiocin and fusidic acid [14,33]. It has also been reported that deletion of acrD does not cause hypersusceptibility to amphiphilic drugs [36,37], which may be due to low expression levels during cellular growth [14]. We have been able to detect similar low expression levels of acrD in E. amylovora Ea1189 during growth in LB broth (Figure 1A). Moreover, we were unable to detect hypersusceptibility to any of the tested antimicrobial compounds in an acrD-deficient mutant (Table 1).

As noted for other bacteria, the overproduction of AcrD in an acrB-deficient host led to increased resistance towards detergents, novobiocin and fusidic acid [14,35]. Overproduction of AcrD in an acrB-deficient mutant of E. amylovora Ea1189 increased the resistance to several antimicrobial compounds and heavy metals. It is noteworthy that expression of $a c r D$ under control of the lac promoter displayed only a minor effect on the resistance level compared to $a c r D$ expression driven by a combination of the lac promoter and the native promoter (up to 16-fold changes in MICs, Table 1). It has previously been reported that strong overproduction of AcrD may interfere with normal activity of the pump [14].
In this study, we identified two new substrates, clotrimazole and luteolin, which increased the substrate spectrum of AcrD in enterobacteria. Clotrimazole is a derivative of imidazole, commonly used in the treatment of fungal infections, and acts primarily by inhibiting the activity of cytochrome P450 mono-oxygenase [38]. Luteolin is one of the most common flavonoids present in many plant families. One of the functions of flavonoids in plants is their protective role against microbial invasion. Luteolin was shown to inhibit bacterial $\mathrm{N}$-acetyltransferase activity [39].

Since AcrD conferred resistance to aminoglycosides in E. coli [13], we hypothesized that AcrD of E. amylovora would display a similar substrate spectrum. However, overexpression of AcrD in E. amylovora Ea1189-3 did not increase the MICs of the aminoglycosides amikacin, gentamicin, streptomycin, and tobramycin. Although it is important to note that we observed occasional, but not reproducible, 2-fold differences between the aminoglycoside MICs for different experiments (data not shown). While this result is contradictory to previous findings for E. coli [13], it may reflect a possible adaptation of the AcrD transporter to a particular physiological function during growth in the plant environment.

To elucidate the role of AcrD in the plant environment, we analyzed whether this RND-type efflux pump is involved in pathogenesis of the plant pathogen. Previously, we have observed that disruption of the AcrB efflux pump in E. amylovora significantly reduced virulence on apple rootstock [16]. This prompted us to evaluate the effect of AcrD on the virulence of the fire blight pathogen by studying development of disease symptoms. However, 
one week after inoculation, the wild type as well as the acrD-deficient mutant conferred typical symptoms on all inoculated shoots, indicating that the disruption of the efflux pump had negligible impact on virulence on apple rootstock. As the host range of E. amylovora also includes pear trees, we further investigated the virulence of the wild type and its acrD-deficient mutant on immature pear fruits (cv. 'Bartlet') with the conclusion that AcrD is not involved in the interaction of the fire blight pathogen with this host.

Additionally, we studied the expression levels of the AcrAB and AcrD efflux pumps in vitro and in planta, respectively. The activity of the acrA promoter was lower in planta than in LB medium (Table 3). However, it is possible that growth of the bacteria in LB broth may increase expression of the AcrAB pump. A similar induction of the RND-type efflux system MexAB-OprM in Pseudomonas syringae was observed during growth in complex King's B medium [40]. Specific components of the complex media might induce the expression of these RND efflux systems. Alternatively, the efflux pumps may play a role in the secretion of metabolites during exponential growth of bacteria in complex medium.

The level of $a c r D$ expression was low during growth in LB medium (Figure 1B), whereas it was slightly induced in planta (Table 3) indicating that plant-derived compounds are able to induce the AcrD pump. The nature of these compounds remains to be elucidated.

Several multidrug transporters are induced in response to the presence of toxic substances [18]. We identified the substrates deoxycholate, naringenin, tetracycline, novobiocin, fusidic acid, tannin and zinc as inducers of $a c r D$ in E. amylovora. In prokaryotes, the expression of drug transporter genes is frequently mediated by transcriptional regulatory proteins, whose genes are often located adjacent to those encoding the transport system. However, no local transcriptional regulator was identified flanking the $a c r D$ gene in E. amylovora, suggesting that expression of acrD may be subject to regulation at the global level.

The acrD gene belongs to the regulon of the envelope stress response, two-component system BaeSR in E. coli and Salmonella enterica. A baeSR-deficient mutant of $E$. amylovora Ea1189 has previously been evaluated for virulence on immature pears, and exhibit full-virulence, as that of wild type, on immature pear fruits [41]. The core regulon of BaeSR consists of spy, encoding a protein chaperon, and the RND efflux pump genes $a c r D$ and $m d t A B C$ [42]. Interestingly, we identified a partial overlap between the compounds inducing expression of $a c r D$ in E. amylovora and baeR in E. coli, e.g., flavonoids (naringenin), zinc, and tannin [24,42]. Accordingly, the contribution of the two-component system BaeSR to regulation of the acrD gene in E. amylovora became of particular interest to us. In E. coli and S. enterica, BaeR, upon activation by phosphorylation through BaeS, binds to the upstream promoter region of $m d t A$ and $\operatorname{acrD}[19,35]$. Our results showed that BaeR of E. amylovora is able to bind the promoter region of $a c r D$ in E. amylovora, but not to the promoter regions of acrA or tolC (Figure 4). Additional investigation of the regulatory networks controlling expression of $a c r D$ in growth cultures and in natural environments, such as within host plants, will need to be conducted in order to provide further insights into the role of this multidrug transporter in the physiology of the cell.

In summary, we have identified a homologue of the RND-type multidrug efflux pump AcrD in E. amylovora Ea1189. Despite the fact that AcrD of Ea1189 was unable to efflux aminoglycosides, we detected a similar substrate spectrum compared to homologues of AcrD from other enterobacteria. Finally, we identified two substrates, clotrimazole and luteolin, hitherto unreported as substrates of AcrD in E. coli and S. enterica.

\section{Conclusions}

The aim of the present study was the characterization of AcrD, a RND-type multidrug efflux pump from the plant pathogen E. amylovora, causing fire blight on apple and pear. Our results demonstrated that AcrD plays a role in drug resistance to a limited number of amphiphilic compounds. We showed that the substrate specificity of AcrD from E. amylovora and of AcrD from E. coli is partly overlapping. However, in contrast to AcrD from E. coli, AcrD from $E$. amylovora cannot provide resistance towards aminoglycosides. The expression of $a c r D$ was up-regulated by the addition of several substrates and was found to be regulated by the envelope stress two-component regulatory system BaeSR. An acrD mutant showed full virulence on apple rootstock and immature pear fruits.

\section{Methods}

\section{Bacterial strains, plasmids and growth conditions}

Bacterial strains and plasmids used in this study are listed in Table 4. E. amylovora strains were cultured at $28^{\circ} \mathrm{C}$ in Lysogeny Broth (LB) or on LB plates. E. coli XL-1 Blue was used as cloning host. $E$. coli cells were routinely maintained at $37^{\circ} \mathrm{C}$ in $\mathrm{LB}$ or double Yeast Trypton (dYT) medium. Cultures harboring individual vectors were supplemented with $50 \mu \mathrm{g} / \mathrm{ml}$ ampicillin (Ap) for E. coli or $250 \mu \mathrm{g} / \mathrm{ml}$ for E. amylovora, $25 \mu \mathrm{g} / \mathrm{ml}$ chloramphenicol $(\mathrm{Cm}), 2 \mu \mathrm{g} / \mathrm{ml}$ gentamicin $(\mathrm{Gm})$ and $25 \mu \mathrm{g} / \mathrm{ml}$ kanamycin $(\mathrm{Km})$ when necessary. Bacterial growth was monitored using a spectrophotometer at $600 \mathrm{~nm}\left(\mathrm{OD}_{600}\right)$.

PCR amplifications, modifications and protein purification Primers (see Additional file 6) were designed based on $E$. amylovora CFBP1430 genome sequences available from NCBI (GenBank NC_013961.1). Screening PCR reactions 
Table 4 Bacterial strains and plasmids used in this study

Plasmid or strain

Plasmid

PJET1.2

PCAM-MCS

pFCm1

pCAM-Km

pCAM-Km.acrD-Cm

pBlueScript II SK(+)

pBluescript II KS(+)

pBBR1MCS

pBluekS.acrD

pBlueKS.acrD-ext

pBlueSK.acrD

pBlueSK.acrD-ext

pBBR.egfp.TIR

pBBR.acrD-Pro.egfp

pBBR.acrA-Pro.egfp

pBlueSK.baeR

pET-28a(+)

pET28a.baeR

pCP20

pBAD24

pBAD24.baeR

\section{Strain}

Escherichia coli

XL1-Blue

TG1

KAM3

BL21(DE3)

S17-1

S17-1 $\lambda$-pir

$\mathrm{DH} 5 \mathrm{a} \lambda$-pir
Relevant characteristics or genotype ${ }^{\mathrm{a}}$

Reference or source

$A p^{r}$, rep (pMB1) from $p M B \mid$ responsible for replication

Thermo scientific

Ap ${ }^{r}$, pCAM140-derivative without mini-Tn5, contains the MCS of pBluescript II SK (+)

[16]

$A p^{r}, \mathrm{Cm}^{r}$, source of $\mathrm{Cm}^{r}$ cassette flanked by FRT sequences

[43]

$\mathrm{Km}^{r}$, variant of the gene replacement vector pCAM-MCS, Ap ${ }^{r}$ replaced by $\mathrm{Km}^{\mathrm{r}}$

This study

This study

$\mathrm{Km}^{\mathrm{r}}, \mathrm{Cm}^{\mathrm{r}}$, contains a 1.1-kb fragment of acrD from E. amylovora Ea1189, insertion of 1153-bp Cm-FRT cassette from pFCm1 in BamHI site

Ap ${ }^{r}$, ColE1 origin

Stratagene

Ap ${ }^{r}$, ColE1 origin

Stratagene

$\mathrm{Cm}^{r}$, ColE1 origin

[44]

$\mathrm{Ap}^{\mathrm{r}}$, contains a 3.1-kb fragment carrying acrD of E. amylovora Ea1189 under control of lac promoter

$\mathrm{Ap}^{\mathrm{r}}$, contains a 3.5-kb fragment carrying acrD of E. amylovora Ea1189 including promoter region under control of lac promoter

$\mathrm{Ap}^{\mathrm{r}}$, contains a 3.1-kb fragment carrying acrD of E. amylovora Ea1189 in opposite orientation with respect to lac promoter

$\mathrm{Ap}^{\mathrm{r}}$, contains a $3.5-\mathrm{kb}$ fragment carrying $\mathrm{acrD}$ of E. amylovora Ea1189 including promoter region in opposite orientation with respect to lac promoter

$\mathrm{Cm}^{r}$, contains the TIR-egfp-T cassette in pBBR1MCS in opposite orientation with respect to lac promoter

$\mathrm{Cm}^{r}$, contains a 206-bp fragment carrying the promoter region of acrD, transcriptional fusion of $a c r D$ with egfp

$\mathrm{Cm}^{r}$, contains a 133-bp fragment carrying the promoter region of acrA, transcriptional fusion of acrA with egfp

$A p^{r}$, contains a 0.7-kb fragment carrying baeR of E. amylovora Ea1189 under control of lac promoter

$\mathrm{Km}^{\mathrm{r}}$, f1 origin

This study

This study

This study

This study

[16]

This study

This study

This study

Novagen

This study

$\mathrm{Km}^{\mathrm{r}}$, contains a 0.7-kb fragment carrying baeR of E. amylovora Ea1189, C-terminal translational fusion with His-tag

$\mathrm{Cm}^{r}, \mathrm{Ap}^{r}$, contains yeast Flp recombinase gene, rep (pSC101) responsible for temperature-sensitive replication

Ap ${ }^{r}$, pMB1 origin, araC

$\mathrm{Ap}^{\mathrm{r}}$, contains a 0.7-kb fragment carrying baeR of E. amylovora Ea1189 under control of $\mathrm{P}_{\mathrm{BAD}}$ promoter

This study

Stratagene

endA1 gyrA96(nal $\left.\left.\right|^{R}\right)$ thi-1 recA1 relA1 lac glnV44 F' $:: \operatorname{Tn}_{10}$ proAB $^{+}$lacl $^{q} \Delta($ lacZ)M15] hsdR17( $\left.r_{k}^{-} m_{k}^{+}\right)$

K-12 supE thi-1 $\Delta$ (lac-proAB) $\Delta$ (mcrB-hsdSM)5, $\left(r_{\mathrm{K}}^{-} \mathrm{m}_{\mathrm{K}}^{-}\right)$

[47]

$a c r A B$ mutant of TG1

[48]

$\mathrm{F}^{-}$ompT gal dcm lon hsdS $S_{B}\left(r_{B}^{-} m_{B}^{-}\right)(\lambda D E 3)$

TpR SmR recA, thi, pro, hsdR-M ${ }^{+}$RP4: 2-Tc:Mu: Km

Novagen

[49]

$\lambda$ pir phage lysogen of S17-1

[49]

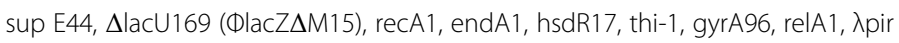
phage lysogen
D. Lies, Caltech 
Table 4 Bacterial strains and plasmids used in this study (Continued)

\begin{tabular}{lll}
\hline Erwinia amylovora & & \\
Ea1189 & Wild type & $\mathrm{GSPB}^{b}$ \\
Ea1189-3 & $\mathrm{Km}^{\mathrm{r}}$, acrB mutant carrying $\mathrm{Km}^{\mathrm{r}}$ cassette in the acrB gene & {$[16]$} \\
Ea1189.acrD & acrD mutant & This study \\
\hline
\end{tabular}

${ }^{a} \mathrm{Ap}^{\mathrm{r}}$, ampicillin resistance; $\mathrm{Cm}^{\mathrm{r}}$, chloramphenicol resistance; $\mathrm{Km}^{\mathrm{r}}$, kanamycin resistance.

${ }^{b}$ GSPB, Göttinger Sammlung Phytopathogener Bakterien, Göttingen, Germany.

were carried out using the DreamTaq DNA polymerase (Thermo Scientific) in accordance with the manufacturer's instructions and optimized annealing temperatures based on the melting temperatures of the respective primers. For high fidelity PCR reactions, Phusion DNA polymerase (Thermo Scientific) was used where the annealing temperature was $3^{\circ} \mathrm{C}$ higher than the lower temperature of the used primer combination.

Restriction enzyme (Thermo Scientific) and T4 DNA ligase (Thermo Scientific) reactions were performed as per the manufacturer's instructions at the appropriate temperature where all ligation reactions were incubated at room temperature.

DNA purifications were either performed using the GeneJET PCR purification kit (Thermo Scientific) or the GeneJET Gel extraction kit (Thermo Scientific) following the manufacturer's instructions.

Protein purification was carried out using the Ni-NTA Spin Kit (Qiagen) following the manufacturer's instructions.

\section{Construction of the E. amylovora acrD-deficient mutant}

A 1058-bp fragment located in the $a c r D$ gene was amplified using the primer pair acrD_ko_fwd and acrD_ko_rev and verified by sequencing. A chloramphenicol cassette flanked by Flp- $F R T$ sites was cut from plasmid pFCM1 and inserted into BamHI-digested pJET.acrD-ko, yielding pJET.acrD-ko.Cm. A 2.2-kb EcoRI fragment cut from pJET.acrD-ko.Cm was ligated into EcoRI-digested pCAM$\mathrm{Km}$, yielding the final replacement plasmid pCAM-Km. acrD-Cm. The plasmid was transformed into electrocompetent cells of $E$. amylovora Ea1189, which subsequently were grown for $3 \mathrm{~h}$ at $28^{\circ} \mathrm{C}$ in dYT broth. Putative mutants were screened for homologous recombination events by testing their antibiotic resistance. Mutants that resulted from single crossover events were identified by their ability to grow on plates containing $\mathrm{Km}$. In order to confirm gene disruption through a double crossover event in $\mathrm{Cm}$ resistant and $\mathrm{Km}$-sensitive colonies, primers acrD_fwd and acrD_rev were designed, which bind upstream and downstream, respectively, of the 1058-bp acrD fragment used for generation of the gene replacement vector. PCRs were done using these locus-specific primers with primers binding in the $\mathrm{Cm}$ cassette (cat_out2, cat_out3, cat_out4, cat_out5). Amplified PCR products were verified by sequencing.
The Cm-FRT cassette was finally excised using the temperature-sensitive plasmid pCP20 that carries the yeast Flp recombinase gene [43,45]. Briefly, Cm-resistant mutants of Ea1189 were transformed with pCP20 and selected at $28^{\circ} \mathrm{C}$ on LB plates containing Ap. Subsequently, Ap-resistant transformants were streaked on non-selective agar plates and incubated at $43^{\circ} \mathrm{C}$ for $1 \mathrm{~h}$; following incubation at $28^{\circ} \mathrm{C}$ for $48-60 \mathrm{~h}$. Single colonies were selected and tested on agar plates containing $\mathrm{Cm}$ or Ap to confirm successful excision of the $\mathrm{Cm}$ cassette and loss of plasmid pCP20.

\section{Construction of $a c r D$ overexpression plasmids}

A 3.06-kb fragment containing acrD was amplified from E. amylovora Ea1189 using the primer pair acrD-ApaI and acrD-SacI. The PCR product was sequenced and further cloned into ApaI-SacI-digested pBlueScript II KS $(+)$ and pBlueScript II SK(+), respectively (pBlueKS.acrD, pBlueSK.acrD).

Next, a 210-bp fragment containing the upstream region of $a c r D$ was amplified using the primers narP-ApaI and acrD_SalI. The PCR product was cloned into a SalI restriction site located in the beginning of the acrD gene (pBlueKS.acrD-ext, pBlueSK.acrD-ext).

\section{Drug susceptibility tests}

The minimal inhibitory concentrations (MIC) of drugs for E. amylovora strains were determined by a 2-fold dilution assay in Mueller-Hinton broth (MHB). All tests were done in at least triplicate following the Clinical and Laboratory Standards Institute recommendations [50]. Growth of bacteria at $28^{\circ} \mathrm{C}$ was examined by visual inspection after $48 \mathrm{~h}$ incubation. The MIC was defined as the lowest concentration of an antibiotic that completely prevented visible cell growth.

\section{Generation of promoter-EGFP fusions}

Transcriptional fusions between the promoter regions of $a c r A$ and $a c r D$, respectively, and $e g f p$ were created using a previously described PCR-based method [51]. Briefly, a 546-bp fragment containing the upstream region of $a c r D$ was amplified using the primer acrD_up and the reverse primer acrD-P-egfp containing a 24-nt extension that is homologous to the start of the egfp gene. The acrA upstream region was amplified using the primer acrAB_fwd 
and the reverse primer acrA-P-egfp. Next, the reporter gene egfp was amplified using the primer pair egfp-ATG and egfp-Cm and the plasmid pBBR.egfp.TIR [16] as the template. All PCR products were gel-purified. For the fusion reaction, $200 \mathrm{ng}$ of a PCR fragment containing a promoter region were mixed with $200 \mathrm{ng}$ of the reporter gene fragment. Nested primer pairs were used for the fusion PCR reactions. For fusion of the acrD promoter to the egfp gene, the primers acrD-P-fwd_SacII-2 and uidA-t0-KpnI were used. The primers acrA-P-fwd-SacII and uidA-t0-KpnI were used in a PCR to fuse the acrA promoter to egfp. The PCR products were gel-purified to remove non-fused fragments. Next, the fusion product was cloned in opposite direction to the lacZ' promoter, into SacII-KpnI-treated pBBR1MCS, yielding plasmids pBBR.acrA-Pro.egfp and pBBR.acrD-Pro.egfp.

\section{Promoter activity of $a c r D$ in vitro}

The reporter gene egfp was employed to study the impact of diverse antimicrobial substances on promoter activities of acrD in E. amylovora. Plasmids carrying the transcriptional fusions were transformed into Ea1189. Antimicrobial compounds were added to the bacterial cells in 96-well microtiter plates by the 2-fold dilution method as described for MIC assays. EGFP fluorescence of the cells following exposure to various concentrations of the substrates was measured 48 hours after incubation at $28^{\circ} \mathrm{C}$ using the microplate reader Infinite M1000 PRO (Tecan, Crailsheim, Germany) with an excitation wavelength of $470 \mathrm{~nm}$ and emission detection at $516 \mathrm{~nm}$.

Fluorescence values obtained were plotted versus optical density in a scatter plot (see Additional file 5). A best-fit linear regression line was added to the plot and a 95\% confidence interval determined. Data points that did not meet the confidence interval criteria indicate fluorescence values higher than the average, thereby suggesting induction of the $\operatorname{acr} D$ promoter by the respective compound.

To further demonstrate promoter induction, the identified substrates were tested in liquid cultures. Cells of Ea1189 harboring plasmid pBBR.acrD-Pro.egfp were incubated in LB broth supplemented with each substrate for 24 hours, then harvested by centrifugation, resuspended in phosphate-buffered saline, adjusted to an $\mathrm{OD}_{600}$ value of 0.1 and fluorescence determined.

\section{Apple plant material and inoculation procedures}

Apple plants (rootstock Malus MM106) were grown in a greenhouse at 20 to $25^{\circ} \mathrm{C}, 60 \%$ humidity, and $12 \mathrm{~h}$ photoperiod (15,000 lx). E. amylovora Ea1189 and its $a c r D$ mutant, grown on LB agar for $24 \mathrm{~h}$, were resuspended and diluted to a cell density of $1 \times 10^{6} \mathrm{CFU} / \mathrm{ml}$ in sterile demineralized water. Apple plants were inoculated by prick technique [52]. Each bacterial strain was inoculated into one shoot of five single plants. A bacterial suspension $(5 \mu \mathrm{l})$ was placed onto each wound on the shoot tip. Plants were monitored for symptom development daily. Survival of bacteria in plant tissue was examined by reisolation of bacterial cells 1 and 5 day(s) after inoculation, respectively, from $1 \mathrm{~cm}$ of the shoot tip around the inoculation area. Ultimately, five wounds were pooled together, homogenized in $0.9 \% \mathrm{NaCl}$, serially diluted, and spread on LB agar plates. The experiment was repeated in triplicate.

In order to analyze the abundance of $a c r A$ and $a c r D$ mRNA transcripts in E. amylovora Ea1189 during growth in apple rootstock MM106, total RNA was isolated from infected apple shoots 1,4 and 7 day(s) post inoculation, respectively. Five individual wounds were pooled together, homogenized in $0.9 \% \mathrm{NaCl}$ and centrifuged for $2 \mathrm{~min}$ at $4000 \mathrm{rpm}$. The supernatant was transferred to $15 \mathrm{ml}$ killing buffer (20 mM Tris- $\mathrm{HCl}, \mathrm{pH} 7.5 ; 20 \mathrm{mM} \mathrm{NaN}_{3}$ ) [53] and centrifuged for $20 \mathrm{~min}$ at $4000 \mathrm{rpm}$. The supernatant was decanted and the pellet frozen at $-80^{\circ} \mathrm{C}$ for further RNA extraction.

\section{Virulence assay on immature pears}

Virulence of E. amylovora Ea1189 and its acrD mutant was determined on immature pears (cv. 'Bartlet'). Bacteria, grown at $28^{\circ} \mathrm{C}$ on $\mathrm{LB}$ agar plates for $24 \mathrm{~h}$, were resuspended and adjusted to an $\mathrm{OD}_{600}$ of 1.0 in sterile demineralized water for inoculation. Immature pear fruits were surfacesterilized and pricked with a sterile needle as described previously [54]. Wounds were inoculated with $5 \times 10^{6} \mathrm{CFU} / \mathrm{ml}$ and incubated in a humidified chamber at room temperature for 8 days. Disease symptoms were recorded by means of diameter of necrosis surrounding the infection site. Fruits were assayed in triplicates and the experiment was repeated twice.

To analyze gene expression of E. amylovora Ea1189 during growth on pear fruits, immature fruits were cut in slices (approx. $0.5 \mathrm{~cm}$ ). Five slices were inoculated with $100 \mu \mathrm{l}$ of a bacterial suspension adjusted to an $\mathrm{OD}_{600}$ of 1.0 in sterile demineralized water. The suspension was evenly distributed on the slice and incubated for 12 hours in a humidified chamber at room temperature. Next, the upper layer of the surface was scratched from the five slices, resuspended in $25 \mathrm{ml}$ of PBS and centrifuged for $2 \mathrm{~min}$ at $4000 \mathrm{rpm}$. The supernatant was transferred to $15 \mathrm{ml}$ killing buffer and further processed as described above.

\section{RNA isolation and quantitative real-time PCR}

Cell cultures were grown in LB broth until the desired optical densities were achieved. An aliquot containing $15 \times 10^{9} \mathrm{CFU}$ (equivalent of $15 \mathrm{ml} \mathrm{OD} 600$ of 1.0 ) was transferred to $15 \mathrm{ml}$ killing buffer and centrifuged for $20 \mathrm{~min}$ at $4000 \mathrm{rpm}$. The supernatant was decanted and the pellet frozen at $-80^{\circ} \mathrm{C}$ for further RNA extraction.

Total RNA was isolated by acid phenol/chloroform extraction [53]. The obtained RNA was treated with 
DNAse (Ambion/Life Technologies, Darmstadt, Germany) and subsequently checked for purity by gel electrophoresis and determination of the A260/A280 and A260/A230 ratios using a Nanodrop ND-2000 spectrophotometer (Thermo Fischer Scientific). High quality RNA was reverse transcribed and amplified with the OneStep RT-PCR Kit according to the manufacturer's protocol (Qiagen, Hilden, Germany). Template RNA (5 ng) was used in a standard 25- $\mu$ l qRT-PCR reaction with specific primers (see Additional file 6). As negative control, RNA samples without reverse transcriptase were included to detect possible DNA contaminations.

For analysis, a Mastercycler ep realplex ${ }^{2}$ gradient S (Eppendorf, Hamburg, Germany) was used. Cycling parameters included a $15 \mathrm{~min}$ initial denaturation at $95^{\circ} \mathrm{C}$ to activate the DNA polymerase followed by 40 cycles consisting of $15 \mathrm{sec}$ at $95^{\circ} \mathrm{C}, 30 \mathrm{sec}$ at $55^{\circ} \mathrm{C}$ and $30 \mathrm{sec}$ at $72^{\circ} \mathrm{C}$. The final step consisted of $1 \mathrm{~min}$ at $95^{\circ} \mathrm{C}$ and $30 \mathrm{sec}$ at $55^{\circ} \mathrm{C}$. A melting curve analysis with a temperature ramp from $25^{\circ} \mathrm{C}$ to $95^{\circ} \mathrm{C}$ in 20 min was performed at the end of each run to determine specificity of amplified qPCR products.

Each sample was analyzed for gene expression in triplicate. Quantification of mRNA transcripts was performed by the comparative $C_{t}$ method. Briefly, the $C_{t}$ values of the samples of interest were compared with a non-treated sample. All $C_{t}$ values were normalized to the housekeeping gene $\operatorname{rec} A$, which shows constant expression at different ODs and medium compositions as well as similar amplification efficiency to the target genes [55]. The compara-

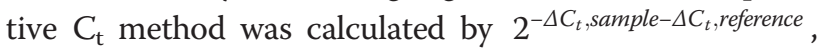
where $\Delta C_{t}$ was normalized to the endogenous housekeeping gene $r e c A$. Subsequently, fold-changes between the samples were determined based on the calculated $\mathrm{C}_{\mathrm{t}}$ method.

\section{Expression of the BaeR protein}

Expression of BaeR was achieved by using the vector pBAD24 where the expression is controlled by the $\mathrm{P}_{\mathrm{BAD}}$ promoter and $\operatorname{araC}$. Therefore, we cloned baeR under control of the arabinose inducible promoter (pBAD24.baeR) and transformed the plasmid into E. amylovora wild-type cells. Protein expression was induced by adding $1 \% \mathrm{~L}$-arabinose when cultures reached an $\mathrm{OD}_{600}$ of 0.5. Cells were further incubated for 1 hour at $28^{\circ} \mathrm{C}$ and subsequently harvested by centrifugation.

\section{Electrophoretic mobility shift assay}

DNA fragments used for the electrophoretic mobility shift assay (EMSA) were PCR amplified using Cy5-labeled primers to perform a non-radioactive EMSA. DNA fragments used were the upstream region of $a c r D(246 \mathrm{bp})$, and as controls, the upstream regions of $a c r A B$ (205 bp) and tolC (291 bp). Approximately $0.16 \mathrm{pmol}$ of Cy5-labeled
DNA was mixed with increasing concentrations of Histagged BaeR protein in a binding buffer reaction $(50 \mathrm{mM}$ Tris-HCl, pH 7.5; 1 mM DTT; $500 \mathrm{mM} \mathrm{MgCl}$; $100 \mathrm{mM}$ EDTA; $10 \mathrm{mM} \mathrm{NaCl}$; $5 \%$ glycerol). To decrease unspecific binding, 500 ng competitor DNA (Salmon sperm DNA, AppliChem) was added to the reaction. Incubation was done at room temperature for $30 \mathrm{~min}$. The total reaction was run on a native $4 \%$ polyacrylamide gel in $0.5 \mathrm{x}$ Tris-borate-EDTA (TBE) buffer at constant $25 \mathrm{~mA}$. After electrophoresis, fluorescence signals of the labeled DNA were visualized using a FLA-3000 phosphorimager (Raytest, Straubenhardt, Germany).

\section{Statistical analysis}

Statistical analysis was performed using R [56]. Differences between two groups were determined by a two-sided $t$-test with equal variances and were considered significant at $\mathrm{P}<0.05$. When necessary the standard deviation is presented in the graph when the average of several values was applied.

\section{Additional files}

\begin{abstract}
Additional file 1: Phylogenetic tree of AcrD. Description: The tree was calculated based on AcrD from Erwinia amylovora Ea1189 (black arrow) and its homologues from other members of the Enterobacteriaceae family, including Erwinia pyrifoliae (95\% identity), E. tasmaniensis (93\% identity), E. billingiae (83\% identity), Pantoea agglomerans (82\% identity), P. ananatis (79\% identity), Enterobacter cloacae (79\% identity), Salmonella enterica (79\% identity), Citrobacter koseri (79\%), Klebsiella pneumoniae (79\% identity), Escherichia coli (78\% identity) and Shigella flexneri (78\% identity). The dendrogram was generated based on percentage of identity between the sequences using the neighbor joining algorithm implemented in Jalview [25-28].
\end{abstract}

Additional file 2: Sequence alignment of AcrD from Erwinia amylovora Ea1189 and Escherichia coli K-12. Description: The alignment is based on the amino acid sequences of AcrD using ClustalW for analysis and Jalview for data presentation. AcrD of Ea1189 is 79\% identical and $89 \%$ similar to AcrD of E. coli K-12. Identical amino acid residues are shown in blue. Yellow bars show a quantitative measurement of conserved physico-chemical properties where the highest score shows amino acids of the same physico-chemical class [26-28]. Black bars indicate predicted transmembrane-spanning helices of AcrD from E. amylovora [29].

Additional file 3: Modified view of the genomic organization of the acrD locus. Description: The locus includes the region from Erwinia amylovora CFBP1430, Escherichia coli K-12 and Salmonella enterica serovar Typhimurium str. LT2, respectively, and was visualized by the Artemis Comparison Tool [57]. The gray areas indicate homologous regions with a minimum identity cutoff score of $88 \%$. The region encoding $a c r D$ is highlighted in light gray. The alignment was performed using the nucleotide search BLASTN from NCBI.

Additional file 4: Membrane protein topology of AcrD from Escherichia coli K-12 (A) and Erwinia amylovora Ea1189 (B). Description: The upper line indicates the predicted topology from TOPCONS [29] based on amino acid sequences. Red lines indicate an inner membrane orientation; blue lines indicate an outer membrane orientation. Grey boxes indicate transmembrane helices spanning from the inside to the outside, white boxes indicate transmembrane helices spanning from the outside to the inside. Below the line is a graphical interpretation of the reliability of the prediction for each amino acid. 
Additional file 5: Scatter plot of the promoter activity of acrD from E. amylovora Ea1189. Description: It shows the effect of substrates on the promoter activity of acrD as determined by a transcriptional fusion with the reporter gene egfp. Antimicrobial compounds were added to cells of Ea1 189 harboring pBBR.acrD-Pro.egfp by the 2 -fold dilution method as described for MIC assays. EGFP fluorescence of the cells following exposure to various concentrations of the substrates was determined after $24 \mathrm{~h}$ incubation. A best-fit linear regression line between fluorescence and optical density values (dashed line) as well as a 95\% confidence interval (solid line) are indicated. Outliers (black spots), showing higher fluorescence than the confidence interval, were identified as follows: deoxycholate (Doc), naringenin $(\mathrm{Ng})$, tetracycline $(\mathrm{Tc})$, and zinc sulfate $(\mathrm{Zn})$. The following substrates were applied to this assay: (+)-catechin, acridine orange, acriflavine, amikacin, azithromycin, benzalkonium chloride, berberine, bile salts, cadmium acetate, chloramphenicol, ciprofloxacin, clarithromycin, clotrimazol, cobalt chloride, copper sulfate, crystal violet, deoxycholate erythromycin, ethidium bromide, fusaric acid, fusidic acid, genistein, gentamycin, josamycin, luteolin, myricetin, naladixic acid, naringenin, nickel chloride, nitrofurantoin, norfloxacin, novobiocin, phloretin, polymyxin B, quercitin, rhodamine $6 \mathrm{G}$, rifampicin, roxithromycin, SDS, silver nitrate, sodium arsenate, sodium tungstate, streptomycin, tetracycline, tetraphenylphosphonium chloride, tobramycin, and zinc sulfate.

Additional file 6: Primers used in this study.

\section{Competing interests}

The authors declared that they have no competing interests.

\section{Authors' contributions}

DP carried out the molecular work, participated in the bioinformatical analysis and drafted the manuscript. HW conceived of the study, participated in its design and coordination and helped to draft the manuscript. All authors read and approved the final manuscript.

\section{Acknowledgments}

This study was supported by Jacobs University Bremen and by the MOLIFE Research Center, Jacobs University Bremen.

Received: 30 September 2013 Accepted: 3 January 2014

Published: 21 January 2014

\section{References}

1. Vanneste J: Fire blight: The disease and its causative agent, Erwinia amylovora. Oxon, UK: CABI Publishing; 2000.

2. Bubán T, Orosz-Kovács ZS, Farkas A: The nectary as the primary site of infection by Erwinia amylovora (Burr.). Plant Syst Evol 2003, 238:183-194.

3. Vanneste J, Eden-Green S: Migration of Erwinia amylovora in host plant tissues. In Fire blight: the disease and its causative agent, Erwinia amylovora. Oxon, UK: CABI Publishing; 2000.

4. Bonn WG, Van der Zwet T: Distribution and economic importance of fire blight. In Fire blight: the disease and its causative agent, Enwinia amylovora. Oxon, UK: CABI Publishing; 2000:37-53.

5. McManus PS, Stockwell VO, Sundin GW, Jones AL: Antibiotic use in plant agriculture. Annu Rev Phytopathol 2002, 40:443-465.

6. Nikaido H: Multidrug efflux pumps of gram-negative bacteria. J Bacteriol 1996, 178:5853-5859.

7. Walsh C: Molecular mechanisms that confer antibacterial drug resistance. Nature 2000, 406:775-781.

8. Piddock L: Multidrug-resistance efflux pumps - not just for resistance. Nat Rev Microbiol 2006, 4:629-636

9. Pos K: Trinity revealed: Stoichiometric complex assembly of a bacterial multidrug efflux pump. Proc Natl Acad Sci U S A 2009, 106:6893-6894

10. Nakamura $\mathrm{H}$ : Gene-controlled resistance to acriflavine and other basic dyes in Escherichia coli. J Bacteriol 1965, 90:8-14.

11. Nikaido H: Antibiotic resistance caused by gram-negative multidrug efflux pumps. Clin Infect Dis 1998, 27(Suppl 1):S32-S41.

12. Ma D, Cook DN, Alberti M, Pon NG, Nikaido H, Hearst JE: Molecular cloning and characterization of acrA and acrE genes of Escherichia coli. J Bacteriol 1993, 175:6299-6313.

13. Rosenberg EY, Ma D, Nikaido H: AcrD of Escherichia coli is an aminoglycoside efflux pump. J Bacteriol 2000, 182:1754-1756.
14. Elkins $C A$, Nikaido $H$ : Substrate specificity of the RND-type multidrug efflux pumps AcrB and AcrD of Escherichia coli is determined predominantly by two large periplasmic loops. J Bacteriol 2002, 184:6490-6498.

15. Poole K, Krebes K, McNally C, Neshat S: Multiple antibiotic resistance in Pseudomonas aeruginosa: evidence for involvement of an efflux operon. J Bacteriol 1993, 175:7363-7372.

16. Burse $A$, Weingart $H$, Ullrich MS: The phytoalexin-inducible multidrug efflux pump AcrAB contributes to virulence in the fire blight pathogen, Erwinia amylovora. Mol Plant-Microbe Interact 2004, 17:43-54.

17. Al-Karablieh N, Weingart H, Ullrich MS: Genetic exchange of multidrug efflux pumps among two enterobacterial species with distinctive ecological niches. Int J Mol Sci 2009, 10:629-645.

18. Grkovic S, Brown MH, Skurray RA: Regulation of bacterial drug export systems. Microbiol Mol Biol Rev 2002, 66:671-701.

19. Nishino K, Honda T, Yamaguchi A: Genome-wide analyses of Escherichia coli gene expression responsive to the BaeSR two-component regulatory system. J Bacteriol 2005, 187:1763-1772.

20. West $A H$, Stock AM: Histidine kinases and response regulator proteins in two-component signaling systems. Trends Biochem Sci 2001, 26:369-376.

21. Parkinson JS: Signal transduction schemes of bacteria. Cell 1993, 73:857-871.

22. Hoch JA, Varughese Kl: Keeping signals straight in phosphorelay signal transduction. J Bacteriol 2001, 183:4941-4949.

23. Raffa RG, Raivio $T L$ : A third envelope stress signal transduction pathway in Escherichia coli. Mol Microbiol 2002, 45:1599-1611.

24. Leblanc SK, Oates CW, Raivio TL: Characterization of the induction and cellular role of the BaeSR two-component envelope stress response of Escherichia coli. J Bacteriol 2011, 193:3367-3375.

25. Livingstone $C D$, Barton $G$ J: Protein sequence alignments: a strategy for the hierarchical analysis of residue conservation. Comput Appl Biosci 1993, 9:745-756.

26. Waterhouse AM, Procter JB, Martin DMA, Clamp M, Barton GJ: Jalview Version 2 - a multiple sequence alignment editor and analysis workbench. Bioinformatics 2009, 25:1189-1191.

27. Sievers F, Wilm A, Dineen DG, Gibson TJ, Karplus K, Li W, Lopez R, McWilliam H, Remmert M, Söding J, Thompson JD, Higgins D: Fast, scalable generation of high-quality protein multiple sequence alignments using Clustal Omega. Mol Syst Biol 2011, 7:539.

28. Goujon M, McWilliam H, Li W, Valentin F, Squizzato S, Paern J, Lopez R: A new bioinformatics analysis tools framework at EMBL-EBI. Nucleic Acids Res 2010, 38:W695-W699.

29. Bernsel A, Viklund H, Hennerdal A, Elofsson A: TOPCONS: consensus prediction of membrane protein topology. Nucleic Acids Res 2009, 37:W465-W468

30. Goyer C, Ullrich MS: Identification of low-temperature-regulated genes in the fire blight pathogen Erwinia amylovora. Can J Microbiol 2006, 52:468-475

31. Wei ZM, Sneath BJ, Beer SV: Expression of Erwinia amylovora hrp genes in response to environmental stimuli. J Bacteriol 1992, 174:1875-1882.

32. Depardieu F, Podglajen I, Leclerca R, Collatz E, Courvalin P: Modes and modulations of antibiotic resistance gene expression. Clin Microbiol Rev 2007, 20:79-114.

33. Nishino K, Yamaguchi A: Analysis of a complete library of putative drug transporter genes in Escherichia coli. J Bacteriol 2001, 183:5803-5812.

34. Fernández L, Hancock RE: Adaptive and mutational resistance: role of porins and efflux pumps in drug resistance. Clin Microbiol Rev 2012, 25:661-681.

35. Nishino K, Nikaido E, Yamaguchi A: Regulation of multidrug efflux systems involved in multidrug and metal resistance of Salmonella enterica serovar Typhimurium. J Bacteriol 2007, 189:9066-9075

36. Ma D, Cook DN, Hearst JE, Nikaido H: Efflux pumps and drug resistance in Gram-negative bacteria. Trends Microbiol 1994, 2:489-493.

37. Sulavik MC, Houseweart C, Cramer C, Jiwani N, Murgolo N, Greene J, DiDomenico B, Shaw KJ, Miller GH, Hare R, Shimer G: Antibiotic susceptibility profiles of Escherichia coli strains lacking multidrug efflux pump genes. Antimicrob Agents Chemother 2001, 45:1126-1136.

38. McLean KJ, Marshall KR, Richmond A, Hunter IS, Fowler K, Kieser T, Gurcha SS, Besra GS, Munro AW: Azole antifungals are potent inhibitors of cytochrome P450 mono-oxygenases and bacterial growth in mycobacteria and streptomycetes. Microbiology 2002, 148:2937-2949. 
39. Chung JG, Hsia TC, Kuo HM, Li YC, Lee YM, Lin SS, Hung CF: Inhibitory actions of luteolin on the growth and arylamine $\mathrm{N}$-acetyltransferase activity in strains of Helicobacter pylori from ulcer patients. Toxicol In Vitro 2001, 15:191-198.

40. Stoitsova SO, Braun Y, Ullrich MS, Weingart H: Characterization of the RND-type multidrug efflux pump MexAB-OprM of the plant pathogen Pseudomonas syringae. Appl Environ Microbiol 2008, 74:3387-3393.

41. Zhao Y, Wang D, Nakka S, Sundin GW, Korban SS: Systems level analysis of two-component signal transduction systems in Erwinia amylovora: role in virulence, regulation of amylovoran biosynthesis and swarming motility. BMC Genomics 2009, 10:245.

42. Zoetendal EG, Smith AH, Sundset MA, Mackie Rl: The BaeSR two-component regulatory system mediates resistance to condensed tannins in Escherichia coli. Appl Environ Microbiol 2008, 74:535-539.

43. Hoang T, Karkhoff-Schweizer RR, Kutchma AJ, Schweizer HP: A broad-host-range FIp-FRT recombination system for site-specific excision of chromosomally-located DNA sequences: application for isolation of unmarked Pseudomonas aeruginosa mutants. Gene 1998, 212:77-86.

44. Kovach ME, Phillips RW, Elzer PH, Roop RM 2nd, Peterson KM: pBBR1MCS: a broad-host-range cloning vector. Biotechniques 1994, 16:800-802.

45. Cherepanov PP, Wackernagel W: Gene disruption in Escherichia coli: $\mathrm{Tc}^{\mathrm{R}}$ and $\mathrm{Km}^{\mathrm{R}}$ cassettes with the option of Flp-catalyzed excision of the antibiotic-resistance determinant. Gene 1995, 158:9-14.

46. Guzman LM, Belin D, Carson MJ, Beckwith J: Tight regulation, modulation, and high-level expression by vectors containing the arabinose PBAD promoter. J Bacteriol 1995, 177:4121-4130.

47. Sambrook J, Russell DW: Molecular cloning: a laboratory manual. Cold Spring Harbor Press: Cold Spring Harbor; 2001.

48. Morita Y, Kodama K, Shiota S, Mine T, Kataoka A, Mizushima T, Tsuchiya T: NorM, a putative multidrug efflux protein, of Vibrio parahaemolyticus and its homolog in Escherichia coli. Antimicrob Agents Chemother 1998, 42:1778-1782.

49. Wilson KJ, Sessitsch A, Corbo JC, Giller KE, Akkermans AD, Jefferson RA: $\beta$-Glucuronidase (GUS) transposons for ecological and genetic studies of rhizobia and other gram-negative bacteria. Microbiology 1995, 141:1691-1705.

50. Clinical and Laboratory Standards Institute: Methods for dilution antimicrobial susceptibility tests for bacteria that grow aerobically. Approved standard, 9th ed. Wayne, PA: CLSI document M7-A7; 2012.

51. Hobert O: PCR fusion-based approach to create reporter gene constructs for expression analysis in transgenic C. elegans. Biotechniques 2002, 32:728-730.

52. May R, Völksch B, Kampmann G: Antagonistic activities of epiphytic bacteria from soybean leaves against Pseudomonas syringae pv. glycinea in vitro and in planta. Microb Ecol 1997, 34:118-124.

53. Schenk A, Weingart $H$, Ullrich MS: Extraction of high-quality bacterial RNA from infected leaf tissue for bacterial in planta gene expression analysis by multiplexed fluorescent Northern hybridization. Mol Plant Pathol 2008, 9:227-235.

54. McGhee GC, Jones AL: Complete nucleotide sequence of ubiquitous plasmid pEA29 from Erwinia amylovora strain Ea88: gene organization and intraspecies variation. Appl Environ Microbiol 2000, 66:4897-4907.

55. Takle GW, Toth IK, Brurberg MB: Evaluation of reference genes for real-time RT-PCR expression studies in the plant pathogen Pectobacterium atrosepticum. BMC Plant Biol 2007, 7:50.

56. Hornik K: R: A language and environment for statistical computing. Vienna, Austria: R Foundation for Statistical Computing; 2013.

57. Rutherford K, Parkhill J, Crook J, Horsnell T, Rice P, Rajandream MA, Barrell B: Artemis: sequence visualization and annotation. Bioinformatics 2000, 16:944-945.

\section{doi:10.1186/1471-2180-14-13}

Cite this article as: Pletzer and Weingart: Characterization of AcrD, a Resistance-Nodulation-Cell Division-type multidrug efflux pump from the fire blight pathogen Erwinia amylovora. BMC Microbiology 2014 14:13.

\section{Submit your next manuscript to BioMed Central and take full advantage of:}

- Convenient online submission

- Thorough peer review

- No space constraints or color figure charges

- Immediate publication on acceptance

- Inclusion in PubMed, CAS, Scopus and Google Scholar

- Research which is freely available for redistribution 